ARTICLE

DOI: $10.1038 / \mathrm{s} 41467-018-05644-0$

\title{
Structural basis for reactivating the mutant TERT promoter by cooperative binding of p52 and ETS1
}

Xueyong Xu1', Yinghui Li', Sakshibeedu R. Bharath', Mert Burak Ozturk (1D ${ }^{1,2}$, Matthew W. Bowler (1) 3,4, Bryan Zong Lin Loo', Vinay Tergaonkar ${ }^{1,2,5}$ \& Haiwei Song ${ }^{1,2}$

Transcriptional factors ETS1/2 and p52 synergize downstream of non-canonical NF-KB signaling to drive reactivation of the $-146 \mathrm{C}>\mathrm{T}$ mutant TERT promoter in multiple cancer types, but the mechanism underlying this cooperativity remains unknown. Here we report the crystal structure of a ternary p52/ETS1/-146C > T TERT promoter complex. While p52 needs to associate with consensus $\kappa B$ sites on the DNA to function during non-canonical NF- $\kappa B$ signaling, we show that $\mathrm{p} 52$ can activate the $-146 \mathrm{C}>\mathrm{T}$ TERT promoter without binding DNA. Instead, p52 interacts with ETS1 to form a heterotetramer, counteracting autoinhibition of ETS1. Analogous to observations with the GABPA/GABPB heterotetramer, the native flanking ETS motifs are required for sustained activation of the $-146 C>$ T TERT promoter by the $\mathrm{p} 52 /$ ETS1 heterotetramer. These observations provide a unifying mechanism for transcriptional activation by GABP and ETS1, and suggest that genome-wide targets of non-canonical NF- $\mathrm{kB}$ signaling are not limited to those driven by consensus $\kappa B$ sequences.

\footnotetext{
${ }^{1}$ Institute of Molecular and Cell Biology, 61 Biopolis Drive, Singapore 138673, Singapore. ${ }^{2}$ Department of Biochemistry, National University of Singapore, 14 Science Drive, Singapore 117543, Singapore. ${ }^{3}$ European Molecular Biology Laboratory, Grenoble Outstation, 71 Avenue des Martyrs, CS 90181,38042 Grenoble, France. ${ }^{4}$ Unit of Virus Host-Cell Interactions, Univ. Grenoble Alpes-EMBL-CNRS, 71 Avenue des Martyrs, CS 90181,38042 Grenoble, France. ${ }^{5}$ Centre for Cancer Biology, University of South Australia and SA Pathology, Adelaide 5001 SA, Australia. These authors contributed equally: Xueyong Xu, Yinghui Li. Correspondence and requests for materials should be addressed to V.T. (email: vinayt@imcb.a-star.edu.sg)

or to H.S. (email: haiwei@imcb.a-star.edu.sg)
} 
T elomeres are tandem TTAGGG sequence repeats found at chromosomal ends that are essential to preserve chromosomal integrity ${ }^{1}$. Telomeres are maintained by the telomerase ribonucleoprotein (RNP) complex ${ }^{2}$. In the absence of telomerase activity, gradual telomeric shortening eventually causes cellular senescence or cell death after progressive cycles of cell division $^{3}$. The catalytic subunit, telomerase reverse transcriptase (TERT), and telomerase RNA component (TERC) constitute the core components of the telomerase ribonucleoprotein (RNP) complex that is essential for maintenance of telomere length ${ }^{4}$. While TERC is ubiquitously expressed in human and murine cells, TERT is transcriptionally silenced in somatic cells and is expressed in detectable amounts only in germ cells and stem cells ${ }^{5}$. Reactivation of TERT leads to cancer progression by canonical (telomere dependent) and non-canonical mechanisms ${ }^{6}$.

As incessant synthesis of telomeric DNA is necessary for unlimited cancer cell proliferation, $85-90 \%$ of human tumors reactivate TERT expression ${ }^{7}$. Undoubtedly, understanding how the dormant TERT promoter is reactivated during carcinogenesis is central to understanding the mechanisms of cancer progression. Two highly recurrent, but mutually exclusive, cancerspecific TERT promoter mutations identified recently have been shown to cause reactivation of TERT promoter in cancers ${ }^{8-12}$. These two $\mathrm{C}>\mathrm{T}$ mutations, located at either -146 or -124 base pairs (bp) upstream of the translational start site of TERT (referred to as $-146 \mathrm{C}>\mathrm{T}$ or $-124 \mathrm{C}>\mathrm{T}$ ), lead to increased telomerase activity and now represent the most common noncoding mutations in cancer $^{13}$. Clinically, these two mutations induce increased telomerase activity and decreased patient survival ${ }^{14,15}$. However, the mechanism by which these single-residue mutations in the human genome cause such a dramatic change in the fate of a cell, by reactivating the expression of the immortalizing enzyme, namely TERT, is poorly understood.

Both $-146 \mathrm{C}>\mathrm{T}$ and $-124 \mathrm{C}>\mathrm{T}$ mutations create an identical 11-bp sequence (5'-CCCCTTCCGGG-3'), containing a putative binding site for E26 (ETS family) transcription factors (GGAA, reverse complement $)^{9}$. Subsequent studies have been performed to identify and characterize the transcription factors which are associated with the reactivation of these two mutant TERT promoters ${ }^{16}$. Recent data demonstrate that three ETS family members-GABPA, ETS1 and ETS2 can bind and activate the mutant TERT promoters ${ }^{17-19}$. The ETS family is a large family of transcription factors existing throughout the metazoan phyla. All ETS family members are defined by the highly conserved DNAbinding ETS domain, which binds similar DNA sequences with a central $5^{\prime}-\mathrm{GGA}(\mathrm{A} / \mathrm{T})-3^{\prime}$ core (ETS motif) ${ }^{20}$. Given that there are 28 ETS family members in humans, the mechanism by which the mutant TERT promoters recruit specific ETS family members remains enigmatic. The specificity for GABPA may reside in its unique feature of obligate multimeric assembly. GABPA heterodimerizes with GABPB, two GABPA/GABPB heterodimers further dimerize through homodimerization of GABPB itself, resulting in a GABP heterotetramer capable of binding two ETS motifs $^{21}$. On the mutant TERT promoters, one GABP heterodimer binds the mutant $-146 \mathrm{C}>\mathrm{T}$ or $-124 \mathrm{C}>\mathrm{T}$ ETS motif, the other binds a tandem flanking native ETS motif ${ }^{17}$. ETS1/2, unlike GABPA, only activate $-146 \mathrm{C}>\mathrm{T}$ mutant TERT promoter through cooperation with $\mathrm{p} 52$ downstream of non-canonical NF- $\mathrm{kB}$ signaling ${ }^{18}$. ETS2 is closely related to ETS1, and they have very similar domains and are essentially identical in their DNAbinding domains. ETS1/2 are in an autoinhibited state, brought about by the inhibitory module flanking the ETS domain $^{22}$. DNA binding of ETS1/2 requires the relief of the autoinhibition by their partner transcription factors bound to adjacent sequences or by palindromic ETS sequence-mediated homodimerization ${ }^{23-26}$. p52 is a member of the NF- $\mathrm{KB}$ family of transcription factors which regulate gene expression in response to a wide array of signaling by binding to consensus $\mathrm{kB}$ sites of $5^{\prime}$-GGGRNYYYCC-3' (R is a purine, $\mathrm{Y}$ is a pyrimidine, and $\mathrm{N}$ is any nucleotide $)^{27}$. The $-146 \mathrm{C}>\mathrm{T}$ TERT promoter does not constitute a palindromic ETS sequence or a consensus $\kappa \mathrm{B}$ site, nor does it contain any other known sequence bound by ETS1 partners. Indeed, how ETS1/2 are selectively recruited to the $-146 \mathrm{C}>\mathrm{T} T E R T$ promoter and how they partner with p52 to activate the mutant TERT promoter is mechanistically unclear. To delineate this mechanism, here we report the crystal structure of $\mathrm{p} 52 / \mathrm{ETS} 1 /-146 \mathrm{C}>\mathrm{T} T E R T$ promoter fragment complex. The structure offers a number of unexpected insights. Structural snapshots combined with cell-based functional assays provide insights into the mechanisms of $-146 \mathrm{C}>\mathrm{T}$ TERT promoter reactivation by $\mathrm{p} 52$ and ETS1/2. While understanding the reactivation of the mutant TERT promoter was the main aim of this study, our results also comprehensively document that NF-kB transcription factors can regulate transcription without specific DNA binding. These results therefore suggest that the number of NF- $\mathrm{kB}$ target genes, which are currently predicted based on existence of consensus $\kappa B$ sites in the upstream regions, could be significantly higher than currently estimated ${ }^{27}$.

\section{Results}

Overall structure. The major domains of ETS1 protein include the PNT domain, the acidic transactivation domain, the ETS DNA-binding domain and autoinhibitory module which consists of inhibitory helix 1 (HI1), inhibitory helix 2 (HI2), helix 4 (H4), and helix $5(\mathrm{H} 5)^{26}$. p52 consists of the Rel homology domain and the glycine-rich region (Fig. 1a) ${ }^{28}$. To investigate the interaction between ETS1 and p52, we performed immunoprecipitation assays in HEK293T cells that were transfected with expression constructs for full-length and truncations of human p52 and ETS1. The region containing the ETS domain and inhibitory elements of ETS1 (residues 267-441), but not the region containing PNT domain and the acidic transactivation domain of ETS1 (residues 1-266), strongly binds to p52. The region of p52 (residues 1-350) containing RHD domain was sufficient to bind to ETS1 (Supplementary Fig. 1a, b).

We next determined the crystal structure of p52-RHD (residues 35-329) in complex with ETS1 $331-441$ and a $15 \mathrm{bp}$ DNA fragment of TERT promoter containing $-146 \mathrm{C}>\mathrm{T}$ ETS motif (designated as p52/ETS1/-146C $>\mathrm{T}$ ) (Supplementary Table 1). The final refined model contains the $15 \mathrm{bp}$ DNA fragment, p52 residues 226-328 designated as the dimerization subdomain of p52-RHD (p52-DSD), and ETS1 residues 332-437 (Fig. 1b, c). The DNA-binding subdomain of p52-RHD (p52DBSD, residues 35-225) is assumed to be disordered as its electron densities are not clear enough for unambiguous model building (Supplementary Fig. 2a). The disorder of p52-DBSD is not due to crystal packing as it can be roughly fitted into the fragmented electron densities without steric clashes with p52DSD, ETS1, and DNA (Supplementary Fig. 2b). The ETS fragment consists of five a helices ( $\mathrm{H} 1, \mathrm{H} 2, \mathrm{H} 3, \mathrm{H} 4$, and $\mathrm{H} 5)$ and four-stranded antiparallel $\beta$ sheets. $\mathrm{H} 1, \mathrm{H} 2$, and $\mathrm{H} 3$ and the $\beta$ sheets comprise the ETS domain. The ETS domain is followed by the $\mathrm{C}$-terminal inhibitory $\mathrm{H} 4$ and $\mathrm{H} 5$ a helices, which pack on the face of the ETS domain opposite the DNA-binding surface. H3 inserts into the major groove of the DNA and contacts the GGAA central core specifically. The p52-DSD is a seven-stranded $\beta$ barrel folding into immunoglobulin-like domain. Flanking both ends of the $\beta$-barrel, there are many loops linking antiparallel $\beta$ strands together. In the p52/ETS1/ $-146 \mathrm{C}>\mathrm{T}$ ternary complex structure, ETS1 recognizes the $-146 \mathrm{C}>\mathrm{T}$ TERT promoter exclusively and concurrently interacts with p52-DSD. 
a

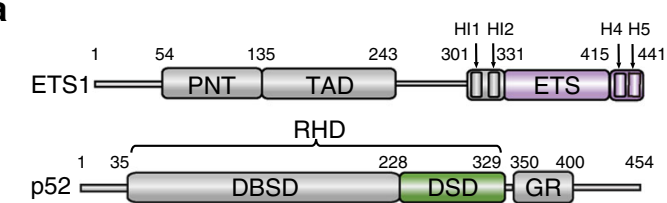

b

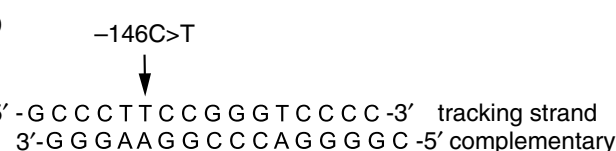

$3^{\prime}-\mathrm{G}$ G GAA G C C CA G G G C - $5^{\prime}$ complementary strand C

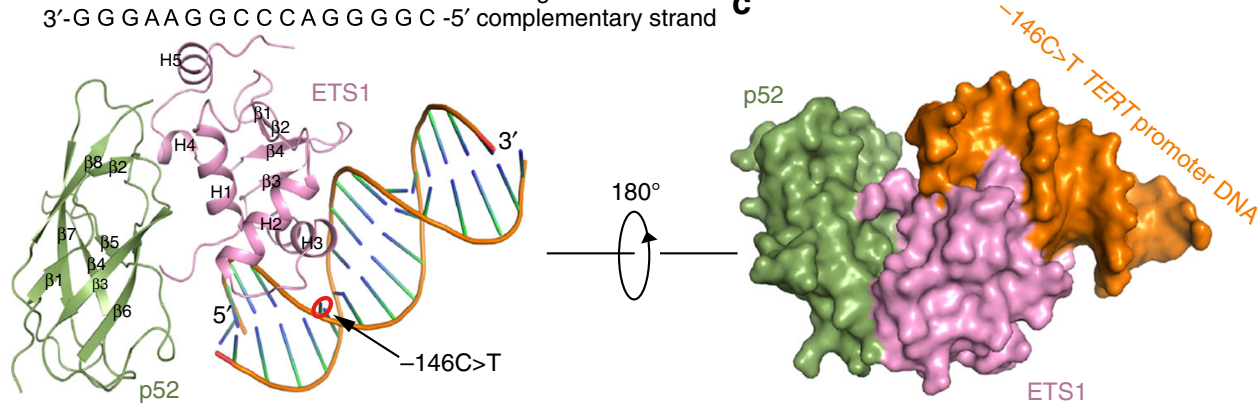

Fig. 1 Overall structure of p52/ETS1/-146C >T mutant TERT promoter complex. a Color-coded domain architecture of human ETS1 and p52. The pink and green color schemes are used in the structural figures of p52/ ETS1/-146C>T TERT promoter fragment complex. PNT PNT domain, TAD acidic transactivation domain, ETS ETS DNA-binding domain, RHD Rel homology domain, DBSD DNA-binding subdomain of RHD, DSD dimerization subdomain of RHD, GR glycine-rich region. b Ribbon diagram of the ternary complex. c Surface representation of the ternary complex

Interaction of p52 with ETS1. The interaction of p52 and ETS1 buries a total solvent accessible surface area of $1187 \AA^{2}$. p52 uses the loops flanking one end of the $\beta$-barrel of p52-DSD to interact with $\alpha$-helices $\mathrm{H} 1, \mathrm{H} 4, \mathrm{H} 5$, loop $\mathrm{H} 4-\mathrm{H} 5$ and $\mathrm{N}$-terminal region of ETS1 domain predominantly through a network of hydrogen bonds and salt bridge contacts, supplemented with additional van der Waals contacts (Fig. 2a). The side chains of Arg241 and Asp275 of p52 form hydrogen bonds with backbone carbonyl group of Thr346 and backbone amide group of Ile335 of ETS1, respectively. Arg241 of p52 also forms salt bridges with Asp347 of ETS1. Met297 and Lys298 of p52 interact with Leu422 of ETS1, via backbone-backbone hydrogen bonds. These interactions are strengthened by a patch of van der Waals contacts between Leu342, Leu422, Tyr424, and Met432 in a hydrophobic cave of ETS1 and Met297 and Leu328 of p52. Met297 of p52 fits snugly into the hydrophobic cave. Although other hydrophobic residues (Leu421, Leu429, Leu433) of ETS1 in this hydrophobic cave do not directly form van der Waals contacts with $\mathrm{p} 52$, they help to stabilize the hydrophobic environment. To confirm these structural findings, we performed mutational analysis of p52. In the structure, the side chain of Arg241 forms salt bridge as well as hydrogen bond with ETS1. Consistent with its important role in the p52/ETS1 interaction, Flag pull-down assays with the purified proteins containing the same regions of p52 and ETS1 in the crystal structure showed that simultaneous mutation of Arg241, Met297, Lys298 participating in p52-ETS1 interaction to alanine $(\mathrm{RMK}>\mathrm{A})$ resulted in marked reduction of p52 affinity with ETS1 (Fig. 2b, Supplementary Fig. 3a). Additional mutation of Leu328 to Glu in the context of $\mathrm{RMK}>\mathrm{A}(\mathrm{RMK}>\mathrm{A} \mathrm{L} 328 \mathrm{E})$ further reduced the binding of p52 to ETS1 (Supplementary Fig. 3b). We also examined the binding thermodynamics of wild type (WT) and $\mathrm{RMK}>\mathrm{A}$ p52 to ETS1 by isothermal titration calorimetry (ITC). WT p52 bound to ETS1 with an equilibrium dissociation constant $\left(K_{\mathrm{d}}\right)$ of $6.76 \mu \mathrm{M}$, whereas the triple mutant showed 5fold reduced binding to ETS1 (Fig. 2c, d).

Sequence alignments indicate that the position of key residue Arg241 of p52 which is significant for the p52/ETS1 interaction is occupied by hydrophobic residues in the counterpart positions of p50, RelA and RelB. Furthermore, most of other residues of p52 in the p52/ETS1 interface are not conserved among NF- $\mathrm{B}$ family members (Supplementary Fig. 4). We next checked the interaction between ETS1 $1_{331-441}$ and the RHD domains of other NF- $\kappa$ B family members (p50, RelA, RelB) by Flag pull-down assays. Although all the four NF- $\kappa B$ family members can interact with ETS1, p52 shows the strongest interaction with ETS1 (Supplementary Fig. 5). The strongest interaction between p52 and ETS1 may play an important role in the process whereby the p52 subunit downstream of non-canonical NF- $\kappa B$ signaling appears to be preferentially selected for synergizing with ETS1/ 2 to drive $-146 \mathrm{C}>\mathrm{T}$ mutant TERT promoter activation. However, the exact mechanism of this phenomenon remains to be further investigated. All the ETS domains of ETS family members are conserved. However, the inhibitory helices H4 and H5 of ETS1/2, which are important for p52 binding, are not conserved among the large ETS transcription factor family in humans (Supplementary Fig. 6), providing a plausible explanation of why only ETS1/2 are selected from ETS transcription factor family to function through the non-canonical NF- $\mathrm{kB}$ signaling to activate $-146 \mathrm{C}>\mathrm{T}$ TERT promoter. These results suggest a functional expansion of targets downstream of non-canonical NF- $\kappa$ B signaling and of targets regulated by ETS1/2 which have not yet been realized previously.

ETS1 rather than p52 binds to $-146 \mathrm{C}>\mathrm{T}$ TERT promoter. ETS1 specifically binds to $-146 \mathrm{C}>\mathrm{T}$ TERT promoter by inserting its H3 helix into the major groove of the ETS motif created by the mutation at -146 position much like that documented previously (Supplementary Fig. 7) ${ }^{24-26}$. p52 alone is unable to specifically bind the $-146 \mathrm{C}>\mathrm{T}$ TERT promoter as a consensus $\kappa \mathrm{B}$ site which is necessary for specific DNA binding by NF- $\kappa B$ family members including p52 is absent from $-146 \mathrm{C}>\mathrm{T}$ TERT promoter. Consistent with this view, ITC data showed that in the absence of ETS1, p52-RHD exhibited nearly negligible binding to the $25 \mathrm{bp}-146 \mathrm{C}>\mathrm{T}$ TERT promoter DNA containing the potential p52-DBSD binding motif of $5^{\prime}$ TCCCC- $3^{\prime}$, which is the part of the $\kappa B$ site (Supplementary Fig. $8 \mathrm{a})$. In contrast, the specific binding affinity between NF- $\kappa \mathrm{B}$ 
a

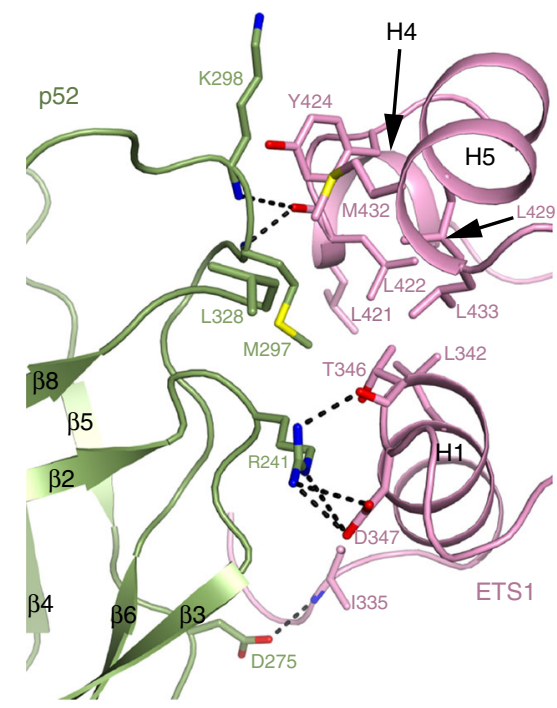

b

C

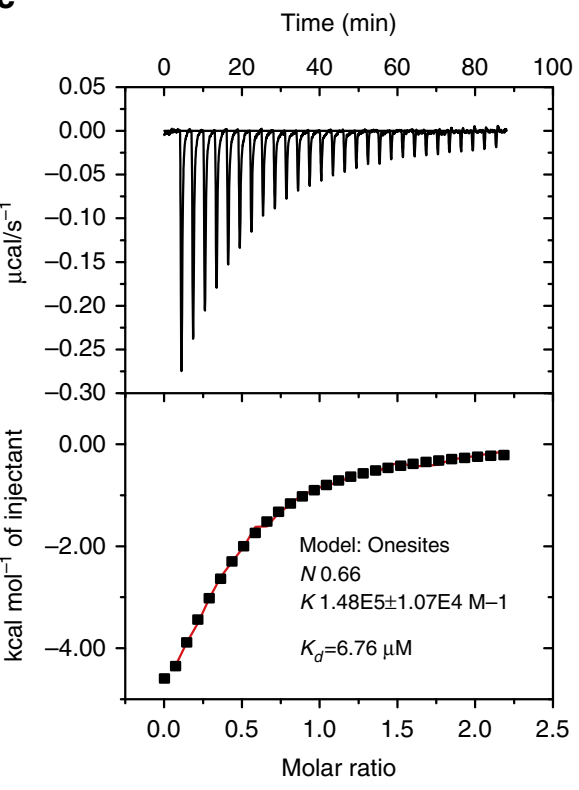

d
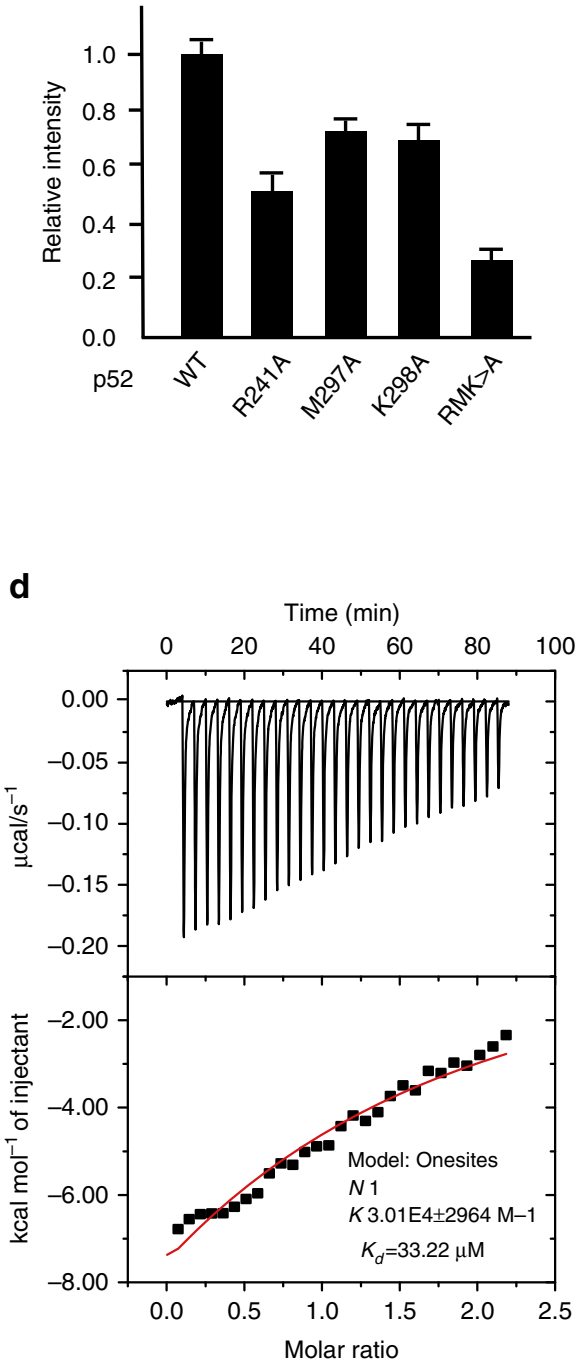

RMK $>$ A p52-RHD versus $\mathrm{ETS}_{331-441}$

Fig. 2 The p52/EST1 interface. a A close-up view of the atomic interactions between p52-DSD and ETS1 $332-437$. b FLAG pull-down assays of p52 and ETS1. The assays were quantified by band densitometry. Error bars, s.d. for triplicate experiments. c, d ITC titrations of ETS1 $1331-441$ with p52-RHD and its RMK $>$ A mutant. The upper panels show the binding isotherms and the lower panels show the integrated heat for each injection fitted to a single-site model

family members and the full $\kappa \mathrm{B}$ sites are reported to be in the $\mathrm{pM}$ to $\mathrm{nM}$ range $\mathrm{e}^{29-31}$. It has been proposed that in cooperation with ETS1, p52 may bind to $-146 \mathrm{C}>\mathrm{T}$ TERT promoter through specific interaction between p52-DBSD and the 5'-TCCCC-3' site $^{18}$. However, our structure shows the contact between p52DBSD and the 5'-TCCC-3' site is sterically blocked by p52DSD and ETS1 (Fig. 3a). ITC data showed that p52-DBSD does not enhance the DNA binding of the ETS1/p52 complex (Fig. 3b, c). An ITC assay using a short $10 \mathrm{bp}-146 \mathrm{C}>\mathrm{T}$ TERT promoter containing only the ETS1-binding site showed that the flanking sequences of the ETS motif have no contribution to the DNA-binding affinity of the p52/ETS1 complex (Fig. 3b, Supplementary Fig. 8b). These observations suggest that p52 does not specifically bind to the $-146 \mathrm{C}>\mathrm{T}$ TERT promoter in vitro, regardless of whether ETS1 is present or not. These results provide structural evidence showing that p52 could activate transcription independent of DNA binding. Indeed, experiments from the Perkins and Oren labs have hinted that p52 can activate transcription without DNA binding ${ }^{32,33}$.

p52 counteracts DNA binding autoinhibition of ETS1. The DNA-binding affinity of ETS1 is regulated by its autoinhibitory module, which is formed predominantly by N-terminal inhibitory helices (HI-1, HI-2) and C-terminal (H4, H5) inhibitory helices flanking the winged helix-turn-helix ETS domain. Chemical shift data from NMR spectra shows that the HI-1 and HI-2 inhibitory helices pack against the $\mathrm{H} 4$ and $\mathrm{H} 5$ inhibitory helices and against helix $\mathrm{H} 1$ of the ETS domain ${ }^{34}$. This compact conformation is known to reduce the DNA-binding affinity of ETS1. However, this autoinhibited state is not immobile. Both hydrogen exchange measurements by NMR and proteolysis studies suggest that HI-1 and HI-2 inhibitory helices are only marginally stable and poised to unfold even in the absence of $\mathrm{DNA}^{34}$. The conformational fluctuation of HI-1 and HI-2 renders a chance to release HI-1 and 
a

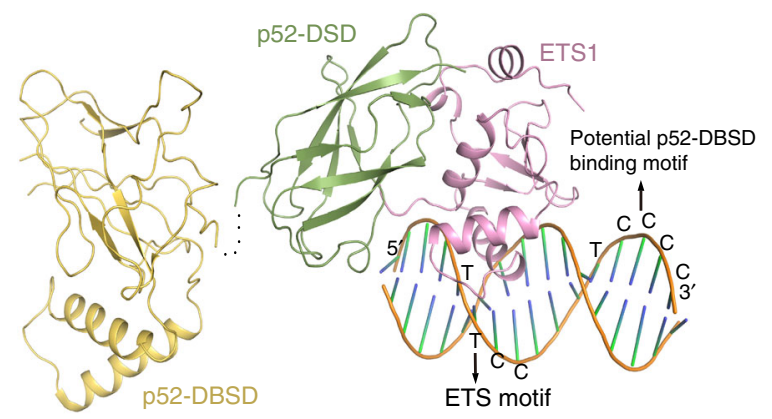

b

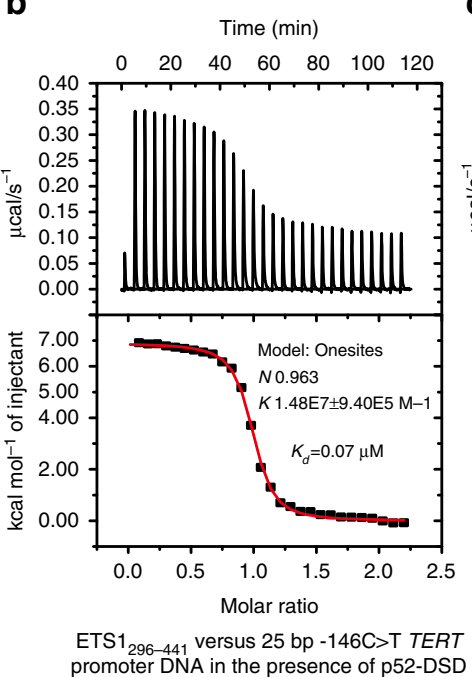

c

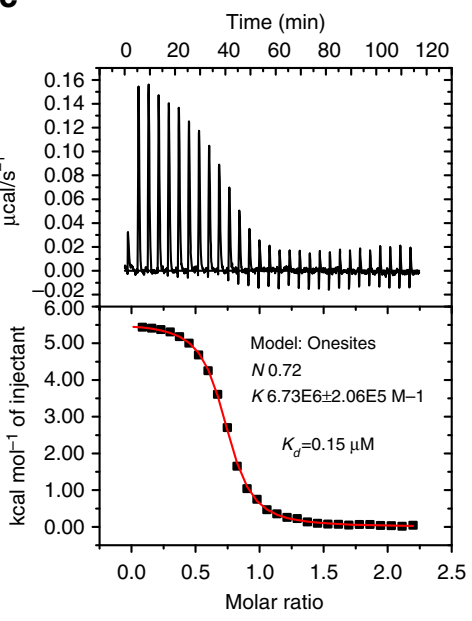

ETS $1_{296-441}$ versus 25 bp $-146 \mathrm{C}>\mathrm{T}$ TERT promoter DNA in the presence of p52-RHD

Fig. 3 p52 does not specifically bind to $-146 C>$ T TERT promoter. a A model showing that p52 would not bind to $-146 C>T$ TERT promoter specifically. The relative orientation between p52-DSD and p52-DBSD showed here is the same as that in the structure of p52 homodimer in complex with DNA (PDB code: 1A3Q). b, c ITC titrations of ETS1 $296-441$ and a 25 bp -146C>T TERT promoter DNA in the presence of p52-DSD (b) or p52-RHD (c)

HI-2 inhibitory helices and to expose the face composed of $\mathrm{H} 1$, $\mathrm{H} 4$ and $\mathrm{H} 5^{34}$. Then both of the released inhibitory helices and the exposed face can be contacted by another ETS1 molecule or by ETS1 partners to counteract the compact autoinhibited state of $\mathrm{ETS1}^{24,26,35}$. Structural superposition of ETS1 in the p52/ETS1/ $-146 \mathrm{C}>\mathrm{T}$ complex and the autoinhibited ETS1 showed that p52DSD and the HI-1 and HI-2 inhibitory helices pack against ETS1 residues 331-441 through overlapping surface regions, suggesting that the HI-1 and HI-2 inhibitory helices would interfere with the binding of ETS1 to p52-DSD (Fig. 4a). Consistent with this, our ITC data showed that ETS1 $1_{296-441}$ containing HI-1 and HI-2 showed threefold reduced binding to p52-RHD (Figs. $2 \mathrm{c}$ and $4 \mathrm{~b}$ ). On the other hand, binding of p52 to ETS1 would displace the HI-1 and HI-2 helices, therefore counteracting the DNA binding autoinhibition of ETS1. In line with this view, ITC data showed that in the presence of p52-DSD, ETS1 $1_{296-441}$ binds to $-146 \mathrm{C}>\mathrm{T}$ TERT promoter DNA with greater affinity. (Figs. $3 \mathrm{~b}$ and $4 \mathrm{c}$, Supplementary Fig. 8b, 8c). The mechanism by which p52 counteracts autoinhibition of ETS1 resembles that of Runx $1^{26}$.

p52 and ETS1 can form a heterotetramer. Homo and heterodimerization of NF- $\kappa \mathrm{B}$ family members are necessary for their diverse physiological roles in vivo ${ }^{27}$. Within the crystal lattice of the p52/ETS1/-146C $>\mathrm{T}$ complex, two p52-DSD molecules homodimerize through a 2-fold crystallographic symmetry (Fig. 5a). Such a p52-DSD homodimer is essentially identical to that observed in the structure of p52 homodimer in complex with the $\kappa B$ site (Supplementary Fig. 9a) ${ }^{28}$, suggesting that the p52/ ETS1 heterodimer can dimerize further via p52 homodimerization to form a heterotetramer. Due to the weak interaction, p52 and ETS1 are always separated in two peaks in gel filtration (Supplementary Fig. 9b). In order to validate the presence of the p52/ETS1 heterotetramer in solution, we performed disulfide crosslinking and examined the molecular weight of the complex using blue native PAGE. The result showed that ETS1 and p52 can indeed form a heterotetramer in solution (Supplementary Fig. 9c, d). GABPA and GABPB, the obligate partners of GABP, also form a heterotetramer. In the GABP heterotetramer, the $\mathrm{N}$ terminal ankyrin repeats of GABPB form a heterodimer with GABPA while the C-terminal leucine zipper-like domain forms a homodimer with itself. Between the N-terminal ankyrin repeats and C-terminal leucine zipper-like domain, there is a long linker (Fig. 5b $)^{21}$. In contrast, the p52/ETS1 heterotetramer is a rigid body whereby p52-DSD mediates both heterodimerization and homodimerization. Therefore, the GABP heterotetramer is much more flexible than the p52/ETS1 heterotetramer. The two GABPA/GABPB heterodimers can swing within a wide range of distance $^{17}$. These findings have implications in the distinction between the activation of $-146 \mathrm{C}>\mathrm{T}$ and $-124 \mathrm{C}>\mathrm{T}$ mutant TERT promoters as discussed below.

The role of flanking native ETS motifs in TERT reactivation. Apart from binding to the mutation-generated ETS motif, GABP heterotetramer also interacts with one of the native ETS binding motifs flanking the mutation site (Fig. $5 c)^{17}$. Since p52 and ETS1 can also form a heterotetramer that interacts with the $-146 \mathrm{C}>\mathrm{T}$ TERT promoter DNA containing two ETS binding motifs (Supplementary Fig. 9e), we next used $-146 \mathrm{C}>\mathrm{T}$ TERT promoterdriven luciferase reporters to investigate the role of native flanking ETS motifs in activation of $-146 \mathrm{C}>\mathrm{T}$ TERT promoter. To test whether the flanking ETS motifs are also required in addition to the p52/ETS1 bound to the mutant site for $-146 \mathrm{C}>\mathrm{T}$ TERT promoter activation, we mutated the flanking ETS motifs and examined their effects on $-146 \mathrm{C}>\mathrm{T}$ TERT promoter. All the three flanking ETS motifs were found to be necessary for full activity of $-146 \mathrm{C}>\mathrm{T}$ TERT promoter, although the effect of $-190 \mathrm{ETS}$ was weaker (Fig. 5d). Since our results were suggestive of the fact that p52 could activate TERT transcription downstream of ETS and not $\kappa \mathrm{B}$ sites, we next analyzed the impact of non-canonical NF- $\kappa \mathrm{B}$ signaling in activating ETS1-dependent transcription of $-146 \mathrm{C}>\mathrm{T}$ TERT promoter. During activation of the non-canonical NF- $\kappa \mathrm{B}$ pathway, stabilization of NF- $\kappa \mathrm{B}$-inducing kinase (NIK) triggers the processing of NF- $\kappa \mathrm{B}$ p100 to $\mathrm{p} 52$, leading to the nuclear accumulation of $\mathrm{p} 52$. Overexpression of NIK alone results in a marked increase in $-146 \mathrm{C}>\mathrm{T}$ TERT promoter activity, which was further elevated with ETS1 overexpression, indicating that p52 and ETS1 can synergistically activate the $-146 \mathrm{C}>\mathrm{T}$ TERT promoter. All the three flanking ETS motifs were necessary for efficient activation of $-146 \mathrm{C}>\mathrm{T}$ TERT promoter by $\mathrm{p} 52 / \mathrm{ETS} 1$ heterotetramer, as mutating any of the three ETS motifs reduced $-146 \mathrm{C}>\mathrm{T}$ TERT promoter activity significantly, either in the presence of stabilized NIK alone or during co-overexpression of 
a

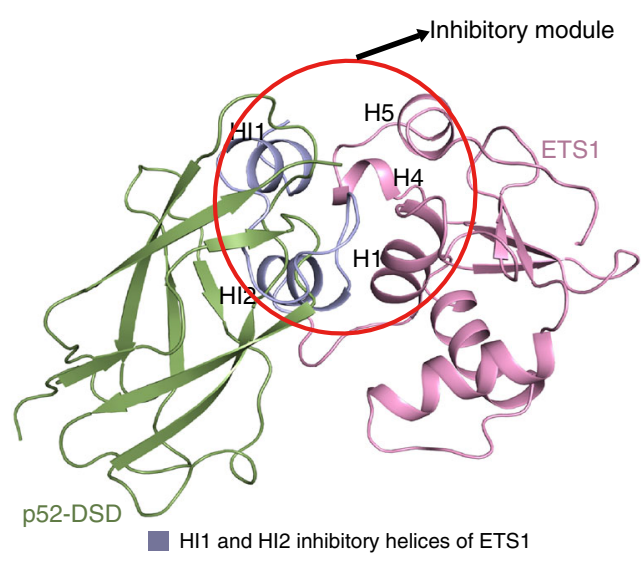

b

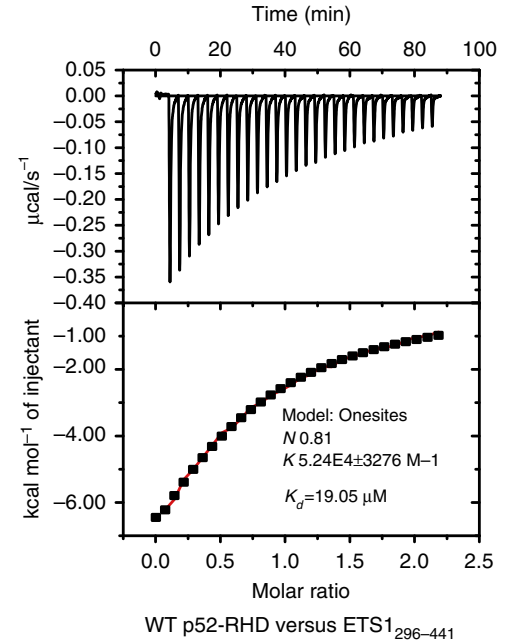

C

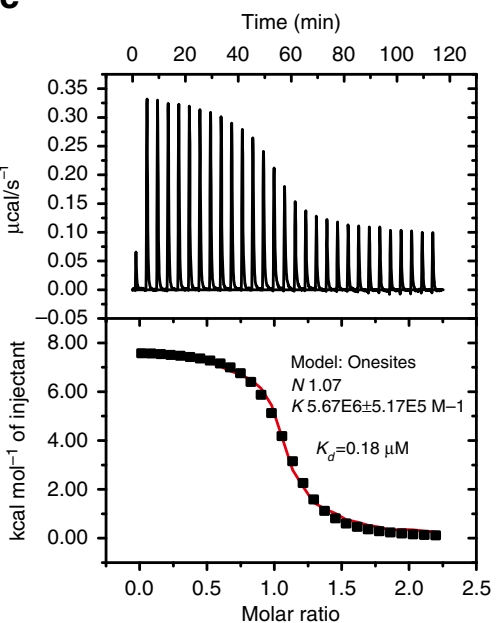

ETS1 ${ }_{296-441}$ versus $25 \mathrm{bp}-146 \mathrm{C}>\mathrm{T}$ TERT promoter DNA in the absence of p52-DSD

Fig. 4 p52-DSD counteracts autoinhibited state of ETS1. a Superposition of the ETS1 molecule of the p52/ETS1/-146C >T complex onto the autoinhibited ETS1 (PDB code: 1R36) shows a steric clash between p52-DSD and the inhibitory helices HI1 and HI2 of ETS1. ETS1 in the p52/ETS1/-146C >T complex is omitted for clarity. b ITC titration of p52-RHD and ETS1 $296-441$ containing the HI1 and HI2 inhibitory helices. c ITC titration of ETS1 $296-441$ and a 25 bp $-146 C>T$ TERT promoter DNA in the absence of p52-DSD

NIK and ETS1 (Fig. 5e). Importantly, a p52 RMK $>$ A mutant which markedly impaired the interaction with ETS1 cannot activate the $-146 \mathrm{C}>\mathrm{T}$ TERT promoter, suggesting that direct interaction between p52 and ETS1 is essential for activation of the $-146 \mathrm{C}>\mathrm{T}$ TERT promoter (Fig. 5f). In support of the crosstalk between p52 and ETS1 in mutant TERT promoter activation, p52 siRNA downregulation in NIK expressing cells led to a decline in ETS1 protein levels, along with the concomitant reduction of $-146 \mathrm{C}>\mathrm{T}$ TERT promoter activity (Fig. $5 \mathrm{~g}$ ). These observations were further substantiated by the significant impairment of $-146 \mathrm{C}>\mathrm{T}$ TERT promoter activity following ETS1 siRNA knockdown, highlighting the critical role of ETS1 in p52-mediated mutant TERT promoter activation (Fig. $5 \mathrm{~g}$ ). In contrast, the $\mathrm{p} 52$ $\mathrm{RMK}>\mathrm{A}$ mutant activated a NF- $\mathrm{kB} 2$ reporter plasmid to a similar extent as wild-type p52 (Fig. 5h), illustrating that mutations in p52 $\mathrm{RMK}>\mathrm{A}$ specifically disrupted the interaction of $\mathrm{p} 52$ with ETS1 that mediated ETS1-dependent transactivation of $-146 \mathrm{C}>\mathrm{T} T E R T$ promoter. All these results reveal that the p52/ETS1 heterotetramer is capable of binding to two ETS motifs to activate $-146 \mathrm{C}>\mathrm{T}$ TERT promoter which could be activated downstream of non-canonical NF- $\mathrm{kB}$ signaling.

\section{Discussion}

Three ETS family members, GABPA, ETS1/2 have currently been identified to activate the $-124 \mathrm{C}>\mathrm{T}$ and $-146 \mathrm{C}>\mathrm{T}$ mutant TERT promoter $^{17,18}$. GABPA has been believed to be unique among the large ETS family, for only GABPA forms a heterotetramer with $\mathrm{GABPB}^{20}$. In this study, we show that p52 and ETS1 also form a heterotetramer. Analogous to the GABP heterotetramer, the p52/ ETS1 heterotetramer can bind to two adjacent ETS motifs in the $-146 \mathrm{C}>\mathrm{T}$ TERT promoter. The $-124 \mathrm{C}>\mathrm{T}$ and $-146 \mathrm{C}>\mathrm{T}$ mutations occur at different frequency in cancers and the levels of TERT expression have been found to be different between the two mutations, suggesting that distinct mechanisms of TERT transcriptional activation exist at the two mutation sites. The $-124 \mathrm{C}>\mathrm{T}$ mutation is predominant in almost all cancers except skin cancers. In skin cancers, the $-124 \mathrm{C}>\mathrm{T}$ and $-146 \mathrm{C}>\mathrm{T}$ mutations occur at almost equal frequency ${ }^{36,37}$. These observations hint that different mechanisms occur in the regulation of the two mutant TERT promoters for different cancers. It has been reported that the GABP heterotetramer activates both $-124 \mathrm{C}>\mathrm{T}$ and $-146 \mathrm{C}>\mathrm{T}$ TERT promoters, but the p52/ETS1 complex was found only to activate the $-146 \mathrm{C}>\mathrm{T}$ TERT promoter ${ }^{17,18}$. What causes this difference is not clear. Our structure shows that the p52/ETS1 heterotetramer is a rigid body, while GABP heterotetramer is much more flexible ${ }^{21}$. The assembly flexibility of GABP heterotetramer allows it to bind two adjacent EST motifs with various spacing ${ }^{17}$. The rigid p52/ETS1 heterotetramer, however, may bind two adjacent ETS motifs with strict spacing. In the $-146 \mathrm{C}>\mathrm{T}$ mutant TERT promoter, the spacing between $-146 \mathrm{C}>\mathrm{T}$ ETS motif and the flanking native motifs is around 50 base pairs. It is possible that $-124 \mathrm{C}>\mathrm{T}$ is too close to the flanking -91ETS and -96ETS native motifs that p52/ETS1 heterotetramer cannot bind to two ETS motifs within such a short distance.

It is widely accepted that NF- $\mathrm{BB}$ members specifically bind to consensus $\kappa B$ sites to activate transcription ${ }^{27}$. However, there are no consensus $\kappa \mathrm{B}$ sites in the WT or mutant TERT promoter for binding by $\mathrm{p} 52$. During p52/ETS1-dependent reactivation of TERT at $-146 \mathrm{C}>\mathrm{T}$ TERT promoter, p52 does not contact DNA to function as a transcription factor. Lacking an activation domain, p52 homodimers alone cannot activate transcription. It functions as an ETS1 partner to counteract ETS1 autoinhibition and as an adaptor to bridge ETS1 to form p52/ETS1 heterotetramer. This atypical function of p52 suggests that noncanonical NF- $\kappa B$ signaling is not limited to regulating the genes harboring consensus $\kappa \mathrm{B}$ sites.

Given that both ETS and NF- $\kappa$ B family are subjects of intense investigation over two decades, it is surprising that the interaction between p52 and ETS1 has not been characterized before. Our results suggest that their interaction is weak $^{38}$, giving a possible explanation why it has been a challenge to characterize. However, this interaction could be specifically required to activate genes with special promoters like TERT which are activated by longrange interactions of multimeric transcription factors ${ }^{39}$. In addition, the weak nature of this interaction could be required to only mildly activate TERT because only 1000 molecules of TERT are present in a cell and that hyperactivation of TERT by stronger activators could cause adverse effects in cancer cells ${ }^{40,41}$. 
Furthermore, since both ETS1 and p52 play key roles in many physiological processes, the weak interaction which can be easily formed and dissociated could provide large ETS1 and p52 reservoirs which are readily available to bind to a multitude of their canonical partners. ETS1 binds to similar sequences with a central 5'-GGA(A/T)-3' core. As this kind of sequences spread widely in the human genome, the function of p52/ETS1 heterotetramer may not be confined to reactivating the $-146 \mathrm{C}>\mathrm{T}$ TERT promoter. It is probable that the p52/ETS1 heterotetramer also binds to other sequences in the genome harboring two adjacent ETS motifs with appropriate spacing. This suggests that noncanonical NF- $\mathrm{KB}$ signaling and ETS1/2 may cooperatively a

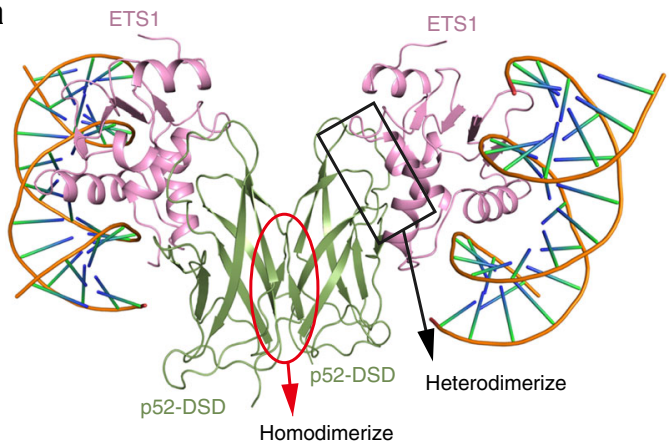

C

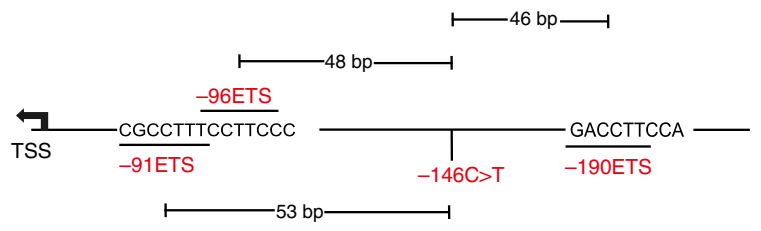

b

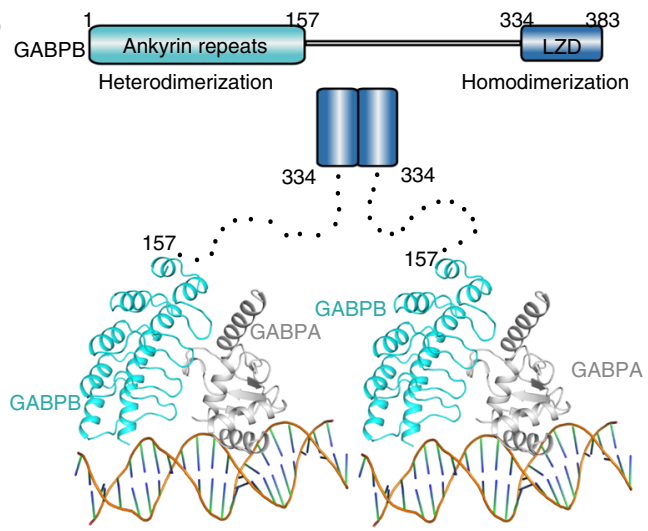

d

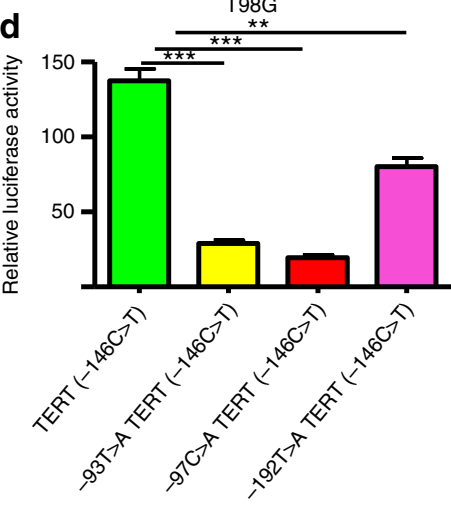

e $\square$ Vector

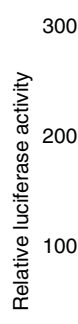

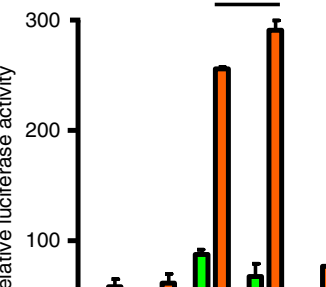

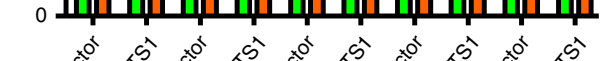
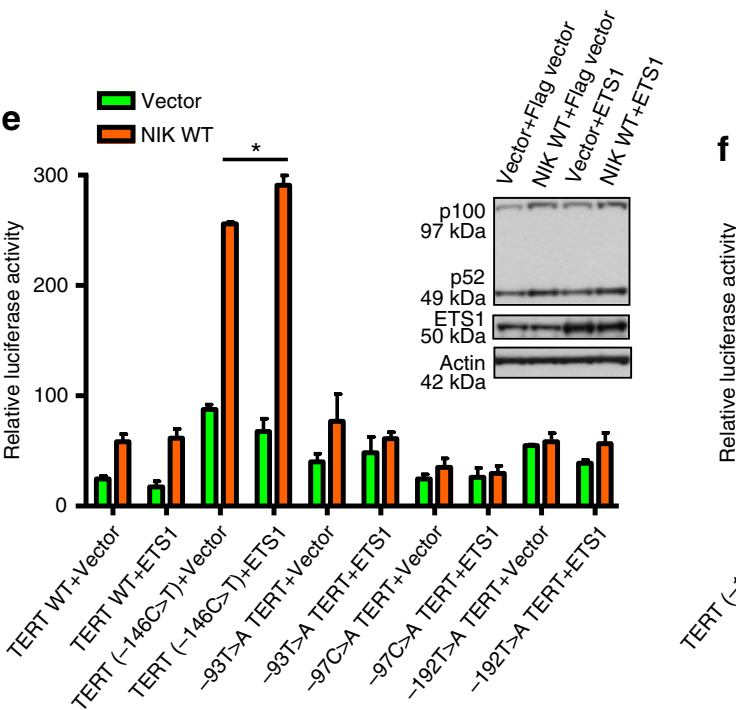

\section{f}

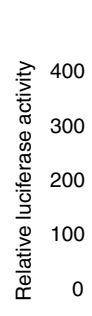

T98G

*
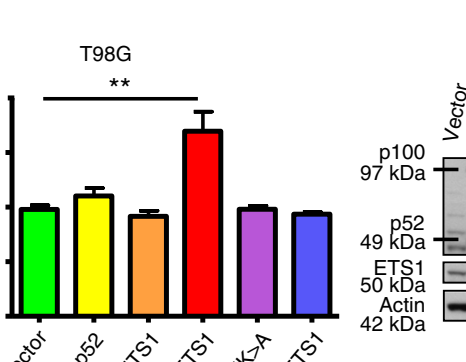

(tin

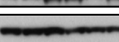
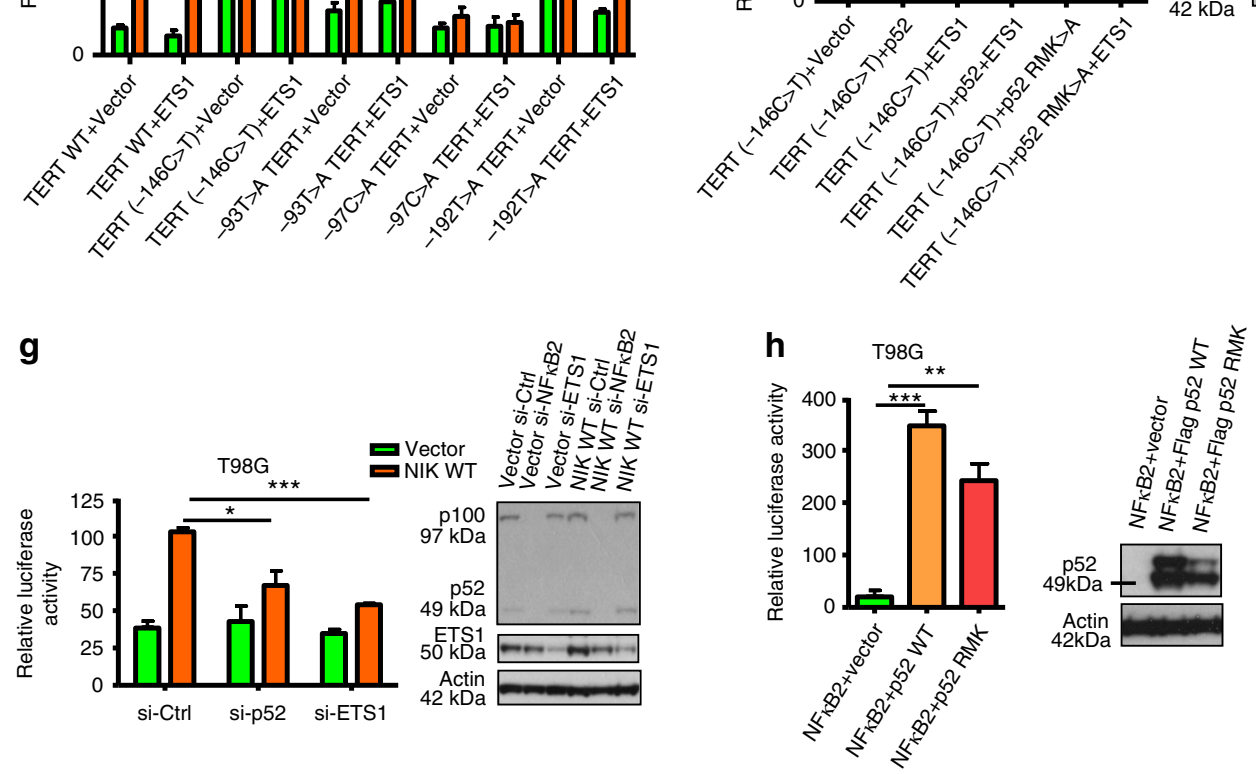
regulate the expression of many other genes besides TERT. Just as their similar function in activation of mutant TERT promoter, p52/ETS1 heterotetramer and GABP heterotetramer may carry out overlapping functions in regulating other genes.

\section{Methods}

Plasmids and DNA preparations. All the constructs for expression in Escherichia coli, which include the RHD domains of RelA (residues 16-291), RelB (residues 111-405), p50 (residues 1-365), and p52 (residues 35-329) as well as p52-DSD (residues 226-328) and $\mathrm{ETS1}_{296-441}$ and $\mathrm{ETS1}_{331-441}$, were cloned into the vector pGEX-6P-1 (GE Healthcare). For Co-immunoprecipitation assay, full-length p52, full-length ETS1, p52 $2_{1-350}, \mathrm{ETS1}_{1-266}$ and $\mathrm{ETS1}_{267-441}$ were cloned into the pBobi mammalian expression vector with either $\mathrm{HA}$ or Flag tag at the $\mathrm{N}$-terminus. Luciferase reporter constructs for wild-type TERT promoter and $-146 \mathrm{C}>\mathrm{T}$ TERT promoter were cloned into the pGL3 basic vector as reported previously ${ }^{15}$. Sitedirected mutagenesis of $\mathrm{p} 52$ in $\mathrm{pBobi}$ vector and $-146 \mathrm{C}>\mathrm{T} T E R T$ promoter reporter constructs in pGL3 vector were performed using the QuikChange Lightning Multi Site-directed Mutagenesis Kit (Agilent Technologies). The NF- кB2 luciferase reporter construct was generated by cloning the NF- $\mathrm{kB} 2$ promoter region $(-1869$ to -1302$)$ into the pGL3 basic vector via XhoI and HindIII restriction enzyme sites.

All of the DNA duplexes used in this study were annealed in a buffer containing $10 \mathrm{mM}$ Tris- $\mathrm{HCl} \mathrm{pH} 7.5$ and $10 \mathrm{mM}$ DTT at concentration of $100 \mu \mathrm{M}$. Annealing was performed by heating at $95^{\circ} \mathrm{C}$ for $10 \mathrm{~min}$ and then put on ice for $10 \mathrm{~min}$. The sequences of the DNA duplexes and mutagenesis primers used are listed in Supplementary Table 2.

Protein purification. All the constructs are expressed in Escherichia coli strain Rosetta2 (DE3) by induction with $0.3 \mathrm{mM}$ isopropyl $\beta$-D-thiogalactopyranoside (IPTG) at $18{ }^{\circ} \mathrm{C}$ overnight. The proteins were initially purified using GST affinity chromatography, followed by PreScission protease cleavage at $4{ }^{\circ} \mathrm{C}$ overnight. The proteins were further purified using heparin affinity chromatography and size exclusion chromatography. To assemble the complex, p52-RHD, ETS1 $1_{331-441}$ and the 15 bp DNA were mixed in a 1:1:1 molar ratio, followed by dialyzing overnight against a buffer containing $10 \mathrm{mM}$ Tris- $\mathrm{HCl}, \mathrm{pH} 7.5$ and $10 \mathrm{mM}$ DTT. The sample was then concentrated to $15 \mathrm{mg} \mathrm{ml}^{-1}$ for crystallization.

Crystallization and structure determination. Crystals of the p52/ETS1/ $-146 \mathrm{C}>\mathrm{T}$ complex were grown at $18{ }^{\circ} \mathrm{C}$ using the setting drop vapor diffusion method by mixing equal volumes of the complex and reservoir solution containing $100 \mathrm{mM}$ HEPES, pH 7.0, 2.0 M ammonium sulfate. Crystals were soaked in a cryoprotectant buffer containing mother liquor and additional $25 \%$ glycerol $(\mathrm{v} / \mathrm{v})$ and were flash frozen in liquid nitrogen. X-ray diffraction data were collected at beamline PX-I (SLS, PSI, Switzerland) and by the autonomous ESRF beamline MASSIF-1 using automatic protocols for the location and optimal centering of crystals (ESRF, Grenoble, France $)^{42,43}$. The beam diameter was selected automatically to match the crystal volume of highest homogeneous quality, in this case $30 \mu \mathrm{m}$. Strategy calculations accounted for flux and crystal volume in the parameter prediction for complete data sets ${ }^{44}$. The data were processed using XDS ${ }^{45}$ and Aimless ${ }^{46}$. The initial phases were obtained by molecular replacement using PHASER ${ }^{47}$ with search model prepared from PDB ID 1K78. The model of the complex was built using $\operatorname{Coot}^{48}$, and then refined by Phenix.refine ${ }^{49}$ and Refmac ${ }^{50}$. A representative portion of electron density map is shown in Supplementary Fig. 10.

Isothermal titration calorimetry. ITC measurements were performed at $8{ }^{\circ} \mathrm{C}$ using MicroCal VP-ITC (MicroCal Inc.). All protein and DNA samples were dialyzed into a buffer containing $25 \mathrm{mM}$ Tris- $\mathrm{HCl} \mathrm{pH} \mathrm{7.5,200} \mathrm{mM} \mathrm{NaCl}$ and 3 $\mathrm{mM}$ TCEP. To obtain the binding affinity between p52 and ETS1, $20 \mu \mathrm{M}$ ETS1 $_{296-441}$ or ETS1 $1_{331-441}$ (in cell) was titrated with $200 \mu \mathrm{M}$ p52-RHD (in syringe). To obtain the binding affinity between $\mathrm{ETS1}_{296-441}$ with $10 \mathrm{bp}$ or $25 \mathrm{bp}$ DNA in the absence or presence of p52-DSD, $10 \mu \mathrm{M} 10 \mathrm{bp}$ or $25 \mathrm{bp}$ DNA in the absence or presence of $100 \mu \mathrm{M}$ p52-DSD (in cell) was titrated with $100 \mu \mathrm{M}$ ETS $_{296-441}$ (in syringe). To obtain the binding affinity between p52-RHD and 25 bp DNA, $10 \mu \mathrm{M} 25$ bp DNA (in cell) was titrated with $100 \mu \mathrm{M}$ p52-RHD (in syringe). To obtain the binding affinity between $\mathrm{ETS1}_{296-441}$ and $25 \mathrm{bp}$ DNA in the presence of p52-RHD, $10 \mu \mathrm{M} 25 \mathrm{bp}$ DNA in the presence of $100 \mu \mathrm{M}$ p52-RHD was titrated with $100 \mu \mathrm{M} \mathrm{ETS1}_{296-441}$ (in syringe). The titration comprised 29 injections of $10 \mu \mathrm{l}$ each, separated by $240 \mathrm{~s}$ equilibration time. The datasets were analyzed using the Origin 7.0 program, fitted to a single-site binding model.

Co-immunoprecipitation. 293 T HEK (ATCC $^{\circ}$ CRL-3216") $^{\prime \prime}$ cells were seeded at a density of $8 \times 10^{5}$ cells per dish in $6 \mathrm{~cm}$ culture dishes and transfected the following day using X-tremeGENE HP DNA transfection reagent (Roche). Cells were cotransfected with $1.5 \mu \mathrm{g}$ each of Flag- or HA-tagged p52 and ETS1 constructs (full length, deletion mutants or amino-acid substitution mutants) and harvested for coimmunoprecipitation assays after 3 days. Protein lysis buffer $(10 \mathrm{mM}$ Tris at $\mathrm{pH} 8$, $170 \mathrm{mM} \mathrm{NaCl}$ and $0.5 \% \mathrm{NP} 40$, supplemented with protease inhibitors) was added to cell pellets, incubated on ice for 15 min prior to sonication for 5 cycles. Lysates were then centrifuged at $14,000 \mathrm{rpm}$ for $15 \mathrm{~min}$ before aspirating $1 \mathrm{ml}$ of each supernatant for immunoprecipitation. Immunoprecipitation of Flag-tagged proteins was performed using $20 \mu \mathrm{l}$ of anti-Flag M2 magnetic beads (packed gel volume) (Sigma: M8823) per sample. Eluted and input protein samples were loaded on a $4-12 \%$ Bis-Tris gel (Invitrogen) and immunoblotting was performed using the following antibodies diluted by 1000 times: anti-Flag (Sigma: F7425), anti-HA (Covance: MMS-101P), anti-Actin (Santa Cruz: sc-1616), anti-HSP90 (Santa Cruz: sc-13119). Uncropped scans of all blots are shown in Supplementary Fig. 11.

Flag pull-down assay. Flag-tagged ETS1 $1_{331-441}$ was incubated with p52-RHD and its mutants, RelA-RHD, RelB-RHD, and p50-RHD in a binding buffer consisting of $50 \mathrm{mM}$ Tris $\mathrm{HCl} \mathrm{pH} 7.4$ and $150 \mathrm{mM} \mathrm{NaCl}$ for $2 \mathrm{~h}$ at $4{ }^{\circ} \mathrm{C}$. The protein samples were then immobilized on $20 \mu \mathrm{l}$ Anti-Flag M2 magnetic beads (Sigma: M8823) for $1 \mathrm{~h}$ at $4{ }^{\circ} \mathrm{C}$. The beads were washed thrice with the binding buffer. The bound proteins were eluted with $250 \mathrm{\mu g} \mathrm{ml}^{-1}$ FLAG peptide and subjected to SDS-PAGE and stained with Coomassie brilliant blue.

Disulfide crosslinking and blue native PAGE. Glu343 of ETS $_{331-441}$ and Arg241 of p52-RHD whose $\mathrm{C} \alpha-\mathrm{C} \alpha$ distance is in the range of that of disulfide bond were mutated to cysteine. At the same time, cysteine on the surface of p52-RHD and ETS $1_{331-441}$ were mutated to serine to prevent non-specific crosslinking. The resultant mutant proteins, p52-RHD (R241C, C57S, and C83S) and ETS1 ${ }_{331-441}$ (E343C and C350S) were kept in a buffer containing $10 \mathrm{mM}$ DTT and then mixed at a molar ratio of 1:2, followed by desalting to remove DTT. The disulfide crosslinking of these two proteins was initiated by addition of $30 \mu \mathrm{M} \mathrm{CuCl}_{2}$ and $100 \mu \mathrm{M}$ phenanthroline for $1 \mathrm{~h}$ at $25^{\circ} \mathrm{C}$. The crosslinking reaction was stopped by the addition of $300 \mu \mathrm{M}$ EDTA for $15 \mathrm{~min}$ at $25^{\circ} \mathrm{C}$. Reversal of crosslinking was carried out by adding $20 \mathrm{mM}$ DTT for $1 \mathrm{~h}$ at $25^{\circ} \mathrm{C}$. The crosslinked and reversed products were checked by $4-16 \%$ gradient blue native PAGE ${ }^{51}$.

Electrophoretic mobility shift assay. Crosslinked p52/ETS1 heterotetramer band was excised from blue native PAGE and mashed by squeezing with a syringe. The gel debris was soaked in double the volume of elution buffer $(25 \mathrm{mM}$ Tris $\mathrm{pH} 7.5$ and $150 \mathrm{mM} \mathrm{NaCl}$ ) overnight. The supernatant containing p52/ETS1 heterotetramer was incubated with FAM labeled $60 \mathrm{bp}$ long $-146 \mathrm{C}>\mathrm{T} T E R T$ promoter DNA for $1 \mathrm{~h}$ at $4{ }^{\circ} \mathrm{C}$ in a buffer containing $20 \mathrm{mM}$ Tris $\mathrm{HCl} \mathrm{pH} 7.5$ and $150 \mathrm{mM}$ $\mathrm{NaCl}$. The samples were subjected to $4-16 \%$ gradient native PAGE and detected by fluorescein signal.

Luciferase reporter assay. T98G human glioblastoma cells (ATCC ${ }^{\oplus}$ CRL-1690") were seeded at a density of $6 \times 10^{4}$ cells per well in 12 -well plates and transfected

Fig. 5 Binding of p52/ETS1 heterotetramer to the $-146 C>$ T mutant TERT promoter. a A ribbon diagram showing a p52/ETS1 heterotetramer bound to $-146 C>$ T TERT promoter DNA observed in the crystal lattice. The regions of $\mathrm{p} 52$ that heterodimerize with ETS1 and homodimerize with itself are indicated. b Color-coded domain architecture of mouse GABPB and a model of GABP heterotetramer (PDB code of the crystal structure showed here: 1AWC). LZD leucine zipper-like domain. $\mathbf{c}-146 \mathrm{C}>\mathrm{T}$ mutation-generated and the tandem flanking native ETS motifs in the core TERT promoter. $\mathbf{d}$ The effect of mutation of adjacent ETS motifs ( $-93 T>A,-97 C>A,-192 T>A$ ) on the activation of mutant TERT promoter. Western blot analyses were performed in parallel to assess the levels of p100/p52 and ETS1 in luciferase reporter assay cells, with actin as a loading control. e The effect of mutation of adjacent ETS motifs ( $-93 T>A,-97 C>A,-192 T>A)$ on the ETS1 and p52-mediated activation of mutant TERT promoter. $\mathbf{f}$ The effect of RMK>A mutant p52 on the activation of mutant TERT promoter. $\mathbf{g}$ The effect of $\mathrm{p} 52$ or ETS1 siRNA during non-canonical NF- $\mathrm{KB}$ signaling in regulation of the $-146 \mathrm{C}>\mathrm{T}$ mutant TERT promoter. $\mathbf{h}$ The effect of RMK $>$ A mutant $\mathrm{p} 52$ on the activation of NF-kB2 reporter plasmid. ${ }^{\star} P<0.05 ;{ }^{\star \star} P<0.01 ;{ }^{\star \star \star} P<0.001$; Student's $t$-test, two-tailed. Error bars in all luciferase reporter assays refer to standard deviations (s.d.) obtained from three independent experiments 
the following day using X-tremeGENE HP DNA transfection reagent (Roche). For reporter assays with NIK, ETS1, p52 WT, or p52 RMK >A expression, T98G cells were infected with the respective lentiviruses to achieve stable expression of the constructs 3 days prior to seeding in 12-well plates. For siRNA treatment, T98G cells were transfected with RNA-lipid complexes of non-targeting control siRNA, NF-kB2 siRNA (L-003918) or ETS1 siRNA (L-003887) (Dharmacon smartpool siRNA) using X-tremeGENE siRNA transfection reagent (Roche) $24 \mathrm{~h}$ prior to transfection with luciferase reporter plasmids. Cells were transfected with $0.3 \mu \mathrm{g}$ each of pGL3 WT TERT promoter or pGL3 -146C $>\mathrm{T} T E R T$ promoter luciferase reporters and $25 \mathrm{ng}$ of Renilla plasmid (Promega) per well. Cells were assayed for luciferase activity 3 days post transfection using the dual luciferase reporter kit (Promega). Triplicate wells were measured for each sample and relative luciferase activity was quantified by normalization of firefly luciferase activity to renilla luciferase activity or protein concentration. Western blot analysis of NIK, ETS1, p52 WT, or p52 RMK>A expressing cells was performed using the following antibodies diluted by 1000 times: anti-NF-kB2 p100/p52 (Cell Signaling; 4882), anti-ETS1 (Santa Cruz; sc-350), anti-Flag (Sigma; F7425), and anti-Actin (Santa Cruz; sc-1616).

Data availability. The atomic coordinates and structural factors for p52/ETS1/ $-146 \mathrm{C}>\mathrm{T}$ complex have been deposited with the Protein Data Bank under accession code 5ZMC, respectively. All other data supporting the findings of this study are available from the corresponding authors on reasonable request.

Received: 2 October 2017 Accepted: 4 July 2018

Published online: 09 August 2018

\section{References}

1. Olovnikov, A. M. A theory of marginotomy. The incomplete copying of template margin in enzymic synthesis of polynucleotides and biological significance of the phenomenon. J. Theor. Biol. 41, 181-190 (1973).

2. Greider, C. W. \& Blackburn, E. H. Identification of a specific telomere terminal transferase activity in Tetrahymena extracts. Cell 43, 405-413 (1985).

3. Armanios, M. Syndromes of telomere shortening. Annu. Rev. Genom. Hum. Genet. 10, 45-61 (2009).

4. Weinrich, S. L. et al. Reconstitution of human telomerase with the template RNA component hTR and the catalytic protein subunit hTRT. Nat. Genet. 17, 498-502 (1997).

5. Ramakrishnan, S., Eppenberger, U., Mueller, H., Shinkai, Y. \& Narayanan, R. Expression profile of the putative catalytic subunit of the telomerase gene. Cancer Res. 58, 622-625 (1998).

6. Khattar, E. et al. Telomerase reverse transcriptase promotes cancer cell proliferation by augmenting tRNA expression. J. Clin. Invest. 126, 4045-4060 (2016).

7. Kim, N. W. et al. Specific association of human telomerase activity with immortal cells and cancer. Science 266, 2011-2015 (1994).

8. Horn, $\mathrm{S}$. et al. TERT promoter mutations in familial and sporadic melanoma. Science 339, 959-961 (2013).

9. Huang, F. W. et al. Highly recurrent TERT promoter mutations in human melanoma. Science 339, 957-959 (2013).

10. Killela, P. J. et al. TERT promoter mutations occur frequently in gliomas and a subset of tumors derived from cells with low rates of self-renewal. Proc. Natl Acad. Sci. USA 110, 6021-6026 (2013).

11. Remke, M. et al. TERT promoter mutations are highly recurrent in SHH subgroup medulloblastoma. Acta Neuropathol. 126, 917-929 (2013).

12. Quaas, A. et al. Frequency of TERT promoter mutations in primary tumors of the liver. Virchows. Arch. 465, 673-677 (2014).

13. Huang, F. W. et al. TERT promoter mutations and monoallelic activation of TERT in cancer. Oncogenesis 4, el76 (2015).

14. Rachakonda, P. S. et al. TERT promoter mutations in bladder cancer affect patient survival and disease recurrence through modification by a common polymorphism. Proc. Natl Acad. Sci. USA 110, 17426-17431 (2013).

15. Borah, S. et al. Cancer. TERT promoter mutations and telomerase reactivation in urothelial cancer. Science 347, 1006-1010 (2015).

16. Bilsland, A. E. et al. Mathematical model of a telomerase transcriptional regulatory network developed by cell-based screening: analysis of inhibitor effects and telomerase expression mechanisms. PLoS Comput. Biol. 10, e1003448 (2014).

17. Bell, R. J. et al. Cancer. The transcription factor GABP selectively binds and activates the mutant TERT promoter in cancer. Science 348, 1036-1039 (2015).

18. Li, Y. et al. Non-canonical NF-kappaB signalling and ETS1/2 cooperatively drive C250T mutant TERT promoter activation. Nat. Cell Biol. 17, 1327-1338 (2015).
19. Stern, J. L., Theodorescu, D., Vogelstein, B., Papadopoulos, N. \& Cech, T. R. Mutation of the TERT promoter, switch to active chromatin, and monoallelic TERT expression in multiple cancers. Genes Dev. 29, 2219-2224 (2015).

20. Hollenhorst, P. C., McIntosh, L. P. \& Graves, B. J. Genomic and biochemical insights into the specificity of ETS transcription factors. Annu. Rev. Biochem. 80, 437-471 (2011).

21. Thompson, C. C., Brown, T. A. \& McKnight, S. L. Convergence of Ets- and notch-related structural motifs in a heteromeric DNA binding complex. Science 253, 762-768 (1991).

22. Hagman, J. \& Grosschedl, R. An inhibitory carboxyl-terminal domain in Ets-1 and Ets-2 mediates differential binding of ETS family factors to promoter sequences of the mb-1 gene. Proc. Natl. Acad. Sci. USA 89, 8889-8893 (1992).

23. Venanzoni, M. C., Robinson, L. R., Hodge, D. R., Kola, I. \& Seth, A. ETS1 and ETS2 in p53 regulation: spatial separation of ETS binding sites (EBS) modulate protein: DNA interaction. Oncogene 12, 1199-1204 (1996).

24. Garvie, C. W., Hagman, J. \& Wolberger, C. Structural studies of Ets-1/Pax5 complex formation on DNA. Mol. Cell 8, 1267-1276 (2001).

25. Babayeva, N. D. et al. Structural basis of Ets1 cooperative binding to palindromic sequences on stromelysin-1 promoter DNA. Cell Cycle $\mathbf{9}$, 3054-3062 (2010).

26. Shrivastava, T. et al. Structural basis of Ets1 activation by Runx1. Leukemia 28, 2040-2048 (2014)

27. Wan, F. \& Lenardo, M. J. Specification of DNA binding activity of NF-kappaB proteins. Cold Spring Harb. Perspect. Biol. 1, a000067 (2009).

28. Cramer, P., Larson, C. J., Verdine, G. L. \& Muller, C. W. Structure of the human NF-kappaB p52 homodimer-DNA complex at 2.1 A resolution. EMBO J. 16, 7078-7090 (1997).

29. Duckett, C. S. et al. Dimerization of NF-KB2 with RelA(p65) regulates DNA binding, transcriptional activation, and inhibition by an I kappa B-alpha (MAD-3). Mol. Cell. Biol. 13, 1315-1322 (1993).

30. Hart, D. J., Speight, R. E., Cooper, M. A., Sutherland, J. D. \& Blackburn, J. M. The salt dependence of DNA recognition by NF-kappaB p50: a detailed kinetic analysis of the effects on affinityand specificity. Nucleic Acids Res. 27, 1063-1069 (1999).

31. Menetski, J. P. The structure of the nuclear factor-kappaB protein-DNA complex varies with DNA-binding site sequence. J. Biol. Chem. 275, 7619-7625 (2000).

32. Schumm, K., Rocha, S., Caamano, J. \& Perkins, N. D. Regulation of p53 tumour suppressor target gene expression by the p52 NF-kappaB subunit. EMBO J. 25, 4820-4832 (2006)

33. Furth, N. et al. Down-regulation of LATS kinases alters p 53 to promote cell migration. Genes Dev. 29, 2325-2330 (2015).

34. Lee, G. M. et al. The structural and dynamic basis of Ets-1 DNA binding autoinhibition. J. Biol. Chem. 280, 7088-7099 (2005).

35. Babayeva, N. D., Baranovskaya, O. I. \& Tahirov, T. H. Structural basis of Ets1 cooperative binding to widely separated sites on promoter DNA. PLOS ONE 7, e33698 (2012)

36. Heidenreich, B. \& Kumar, R. TERT promoter mutations in telomere biology. Mutat. Res. 771, 15-31 (2017).

37. Heidenreich, B. et al. TERT promoter mutations and telomere length in adult malignant gliomas and recurrences. Oncotarget 6, 10617-10633 (2015).

38. Perkins, J. R., Diboun, I., Dessailly, B. H., Lees, J. G. \& Orengo, C. Transient protein-protein interactions: structural, functional, and network properties. Structure 18, 1233-1243 (2010).

39. Akincilar, S. C. et al. Long-range chromatin interactions drive mutant TERT promoter activation. Cancer Discov. 6, 1276-1291 (2016).

40. Akincilar, S. C. et al. Quantitative assessment of telomerase components in cancer cell lines. FEBS Lett. 589, 974-984 (2015).

41. Akincilar, S. C., Unal, B. \& Tergaonkar, V. Reactivation of telomerase in cancer. Cell. Mol. Life Sci. 73, 1659-1670 (2016).

42. Svensson, O., Malbet-Monaco, S., Popov, A., Nurizzo, D. \& Bowler, M. W. Fully automatic characterization and data collection from crystals of biological macromolecules. Acta Crystallogr. D Biol. Crystallogr. 71, 1757-1767 (2015).

43. Bowler, M. W. et al. MASSIF-1: a beamline dedicated to the fully automatic characterization and data collection from crystals of biological macromolecules. J. Synchrotron Radiat. 22, 1540-1547 (2015).

44. Svensson, O., Gilski, M., Nurizzo, D. \& Bowler, M. W. Multi-position data collection and dynamic beam sizing: recent improvements to the automatic data-collection algorithms on MASSIF-1. Acta Crystallogr. D Struct. Biol. 74, 433-440 (2018).

45. Kabsch, W. XDS. Acta Crystallogr. D Biol. Crystallogr. 66, 125-132 (2010).

46. Evans, P. Scaling and assessment of data quality. Acta Crystallogr. D Biol. Crystallogr. 62, 72-82 (2006).

47. McCoy, A. J. et al. Phaser crystallographic software. J. Appl. Crystallogr. 40, 658-674 (2007).

48. Emsley, P. \& Cowtan, K. Coot: model-building tools for molecular graphics. Acta Crystallogr. D Biol. Crystallogr. 60, 2126-2132 (2004). 
49. Adams, P. D. et al. PHENIX: building new software for automated crystallographic structure determination. Acta Crystallogr. D Biol. Crystallogr. 58, 1948-1954 (2002).

50. Murshudov, G. N. et al. REFMAC5 for the refinement of macromolecular crystal structures. Acta Crystallogr. D Biol. Crystallogr. 67, 355-367 (2011).

51. Wittig, I., Braun, H. P. \& Schagger, H. Blue native PAGE. Nat. Protoc. 1, 418-428 (2006).

\section{Acknowledgements}

We would like to thank the beamline scientists at MASSIF-1 (ID30A-1) of ESRF, France for assistance and access to synchrotron radiation facilities. This work was financially supported by the Agency for Science, Technology and Research and Singapore National Research Foundation under its Competitive Research Programme (NRF-CRP17-2017-

02) in Singapore.

\section{Author contributions}

H.S. and V.T. conceived and coordinated the study. X.X., Y.L., S.R.B., M.B.O, M.W.B., and B.Z.L.L. performed the experiments. X.X., Y.L., V.T., and H.S. analyzed the data and wrote the manuscript.

\section{Additional information}

Supplementary Information accompanies this paper at https://doi.org/10.1038/s41467018-05644-0
Competing interests: The authors declare no competing interests.

Reprints and permission information is available online at http://npg.nature.com/ reprintsandpermissions/

Publisher's note: Springer Nature remains neutral with regard to jurisdictional claims in published maps and institutional affiliations.

(c) (i) Open Access This article is licensed under a Creative Commons Attribution 4.0 International License, which permits use, sharing, adaptation, distribution and reproduction in any medium or format, as long as you give appropriate credit to the original author(s) and the source, provide a link to the Creative Commons license, and indicate if changes were made. The images or other third party material in this article are included in the article's Creative Commons license, unless indicated otherwise in a credit line to the material. If material is not included in the article's Creative Commons license and your intended use is not permitted by statutory regulation or exceeds the permitted use, you will need to obtain permission directly from the copyright holder. To view a copy of this license, visit http://creativecommons.org/ licenses/by/4.0/.

(C) The Author(s) 2018 